\title{
Malestar docente: el desplazamiento de la figura del docente como complicidad ideológica del discurso pedagógico ${ }^{1}$
}

\author{
Lic. Prof. Javier Iván Paul \\ javierpaul1@ hotmail.com \\ Instituto Superior del Profesorado San Benito \\ Entre Ríos, Argentina.
}

«No tener maestro es no tener a quién preguntar y más hondamente todavía, no tener ante quién preguntarse.»

María Zambrano

\section{RESUMEN}

Con el propósito de desarticular el ensamblaje conceptual que suele producirse entre el Síndrome de Burnout y el Malestar Docente, proponemos definir a este último como un malestar histórico y social, caracterizado tanto por la descalificación de la posición social del colectivo docente como por el desprestigio de la educación misma. Desde una perspectiva latinoamericana de la Salud Mental Comunitaria y dentro de la consideración de los Determinantes Sociales de la Salud, pretendemos visibilizar los componentes ideológicos que permean el discurso pedagógico como un efecto histórico de sedimentación semántica de cuño neoliberal. Específicamente, delimitamos un Determinante Pedagógico del Malestar Docente -la complicidad ideológica del discurso pedagógico- constituido por el desplazamiento de la figura del docente como correlato narrativo de la descalificación histórica y social del colectivo docente; es decir, el anverso del discurso ideológico neoliberal que podemos develar en la teoría pedagógica bajo la influencia de cierto tipo de teorías psicológicas del aprendizaje.

Palabras Clave: malestar docente; síndrome de burnout; discurso pedagógico; neoliberalismo; violencia simbólica; proceso de concientización.

\footnotetext{
${ }^{1}$ El presente trabajo constituye el informe final de un Seminario sobre Malestar Docente, desarrollado durante el Ciclo Lectivo 2021 desde la cátedra Problemáticas Contemporáneas de la Psicología; en el cuarto año del Profesorado de Educación Secundaria en Psicología, perteneciente al Instituto Superior del Profesorado "San Benito" de la ciudad de Victoria, Provincia de Entre Ríos (Argentina). La metodología del Seminario se desarrolló bajo la modalidad de Aprendizaje por Descubrimiento Guiado cuyo objetivo general consistió en la construcción conceptual del Malestar Docente a partir de la delimitación de sus determinaciones históricas y sociales desde la perspectiva de la Salud Mental Comunitaria.
} 


\title{
Teachers' Malaise: the displacement of the figure of the teacher as an ideological complicity of the pedagogical discourse
}

\begin{abstract}
With the purpose of dismantling the conceptual assembly that usually occurs between the Burnout Syndrome and Teachers' Malaise, we propose to define the latter as a historical and social malaise, characterized both by the disqualification of the social position of the teaching group and by the discredit of education itself. From a Latin American perspective of Community Mental Health and within the consideration of the Social Determinants of Health, we intend to make visible the ideological components that permeate the pedagogical discourse as a historical effect of neoliberal semantic sedimentation. Specifically, we define a pedagogical determinant of teacher malaise -the ideological complicity of the pedagogical discourse- constituted by the displacement of the figure of the teacher as a narrative correlate of the historical and social disqualification of the teaching group; that is to say, the obverse of the neoliberal ideological discourse that we can unveil in pedagogical theory under the influence of certain types of psychological theories of learning.
\end{abstract}

Keywords: teachers' malaise; burnout syndrome; pedagogical discourse; neoliberalism; symbolic violence; awareness process.

Artículo recibido: 30 noviembre. 2021 Aceptado para publicación: 29 diciembre 2021 Correspondencia: javierpaul1@ hotmail.com Conflictos de Interés: Ninguna que declarar 


\section{INTRODUCCIÓN}

Siempre que se hace referencia al Malestar Docente, y aunque se mencionen de soslayo sus determinantes sociales -mucho menos frecuentemente los históricos-, se lo termina asimilando al Síndrome de Burnout. Es necesario señalar que este deslizamiento constituye un triple reduccionismo (positivista, individualista y psicologista) sobre un tema que amerita un análisis un poco más complejo (interdisciplinario) que la simple delimitación sintomática de un síndrome psicológico. Para salir de esta encerrona minimalista, proponemos definir el Malestar Docente como un "malestar históricosocial" caracterizado tanto por la descalificación de la posición social del colectivo docente como por el desprestigio de la educación, considerada en sí misma o como resultado del ejercicio deficiente de la práctica docente.

Esta descalificación colectiva de la educación y de la docencia, debe ser comprendida como un sistema descalificatorio ya que no se dirige directamente al colectivo docente sino a la función estratégica que tiene la Educación en el desarrollo de una Nación y al rol que cumple el Estado como garante del Derecho a la Educación. La permanente desvalorización de la situación actual de la Educación, la crítica indiscriminada a componentes tradicionales de la educación, la idea persistente de que la educación debe cambiar y la insistencia en que la educación debe adaptarse a las condiciones del presente; son las consignas ideológicas que tienen como propósito destituir la Educación como agencia de transformación social. La función estratégica de la escuela, de la educación y de los/as docentes es hacer que la sociedad del presente cambie, tomando como referencia un proyecto de futuro a partir y en continuidad con los logros del pasado; por eso el planteo ideológico-destituyente busca desmantelar justamente estas mismas referencias. Los estudios que suelen realizarse en orden a visibilizar el embate de la ideología neoliberal en el campo educativo, nos permiten identificar y definir las determinaciones históricas y sociales que constituyen el Malestar Docente, que hemos definido a partir de la descalificación histórica-social de la educación y de sus docentes como agentes de cambio. Pero lo que nos proponemos en este trabajo es visibilizar los componentes ideológicos que permean el discurso pedagógico como un efecto histórico de sedimentación semántica de cuño neoliberal. Para ello, haremos una adecuación en la definición que hemos dado del Malestar Docente y señalaremos como rasgo característico el Desplazamiento de la Figura del Docente en la escena pedagógica. 
Consideramos este desplazamiento como el correlato narrativo de la descalificación histórica-social del colectivo docente; es decir, el anverso del discurso ideológico neoliberal que podemos develar en la teoría pedagógica bajo la influencia de cierto tipo de teorías psicológicas del aprendizaje. Es a esto a lo que nos referimos como complicidad ideológica del discurso pedagógico, que no es otra cosa que el señalamiento de un determinante pedagógico correlativo la determinación histórica y social del Malestar Docente.

\section{La patologización del Malestar Docente}

Nuestro propósito consiste en considerar y fundamentar el Malestar Social Docente como un problema de Salud Pública y desde una perspectiva latinoamericana de la Salud Mental Comunitaria. ${ }^{2}$ El recorte que hacemos al referirnos a la salud como "mental" no es más que un reaseguro terminológico utilizado para dar cuenta de una concepción integral de la salud (psicofísica), que no podría ser completa si no se aclara que se trata de pensar en la salud mental de un colectivo de personas (social), no solamente de los individuos. Esta perspectiva se sostiene desde una mirada interdisciplinaria a partir de la consideración de los Determinantes Sociales ${ }^{3}$ [e Históricos] de la Salud, con la finalidad de promover la salud como intervención adecuada para la prevención de enfermedades y padecimientos. Desde este posicionamiento, queremos señalar que la tendencia a asimilar el Malestar Docente con el Síndrome de Burnout es fruto de una perspectiva de análisis que no compartimos:

\footnotetext{
${ }^{2}$ Con esta expresión retomamos la corriente de la Medicina Social Comunitaria que interpreta los procesos de salud-enfermedad de los grupos humanos de manera situada en el contexto de los avatares sociopolíticos de la historia reciente de Latinoamérica: "Desarrollada desde los 70 (...) se constituyó en el tumultuoso período que va desde la crisis global de esa época hasta la actual. Se fue generando en el transcurso de una transformación global de la economía y la geopolítica mundial durante la cual se sucedieron en América Latina dictaduras militares, movimientos de resistencia, una "década perdida" en el desarrollo (los 80), las reformas neoliberales con las crisis del endeudamiento, la emergencia de nuevos movimientos sociales y la aparición de un reordenamiento regional junto con gobiernos de postulados neokeynesianos de diversa índole. Coincidió, a nivel mundial, con la crisis de eficacia de la Salud Pública tradicional por su imposibilidad de dar respuesta a los problemas que se generaban en los colectivos humanos, con la mercantilización extrema de la salud tanto por la apropiación con fines financieros privados de los fondos sociales destinados a ella como por el desarrollo fenomenal de las industria químico farmacéutica y de aparatología médica, y con el avance y reformulación de la medicalización de la vida" (Stolkiner y Ardila Gómez, 2012, p. 58).

${ }^{3}$ Una alternativa a esta denominación es la de "Determinación Social" definida en la declaración de la Asociación Latinoamericana de Medicina Social (ALAMES) conjuntamente con el Centro Brasilero de Estudios de Saude (CEBES) como "categoría de análisis indispensable para trabajar la realidad en sus diversas dimensiones, una respuesta del pensamiento crítico al reduccionismo del pensamiento empírico analítico [positivista] que ha mirado la salud únicamente desde el plano de los factores aislados de una realidad cuyos procesos estructurales no se explican o se ocultan" (Mejía, 2013, p. 29).
} 
En nuestro país se conceptualiza el "burnout" en el ámbito de la docencia como malestar docente, haciendo referencia al complejo proceso en el cual los maestros expresan sus marcas subjetivas y corporales producidas en una tarea soportada a costa de un importante desgaste y sufrimiento. (Devalle de Rendo y Vega, 2004, p. 87)

Dicha conceptualización opera una asimilación semántica entre el término "malestar" y el término "síndrome", generando un triple reduccionismo: positivista, individualista y psicologista. El reduccionismo positivista se produce al cancelar el alcance conceptual y comprensivo del término "malestar" limitándolo a la descripción extensiva de un "síndrome"; en otras palabras, la diferencia estriba en que el término "malestar" constituye una categoría analítica que nos permite comprender (interpretar y analizar) el fenómeno, mientras que el término "síndrome" es una categoría descriptiva que solo nos permite reconocer sus manifestaciones subjetivas. El reduccionismo individualista consiste en que mientras la categoría analítica de "malestar" nos permite hacer una delimitación social o colectiva del fenómeno, la categoría descriptiva de "síndrome" nos remite indefectiblemente a un recorte individual del mismo. El reduccionismo psicologista se produce al delimitar el "síndrome" como un perfil psicológico, mientras que la delimitación del "malestar" nos permite construir un perfil socio-histórico del fenómeno. Solo cuestionamos el reduccionismo que se produce en la definición del malestar por el síndrome, lo cual no significa que desmerezcamos el valor heurístico de la descripción del síndrome para comprender el Malestar Docente.

Otra cuestión a tener en cuenta en las limitaciones conceptuales de las investigaciones del Síndrome de Burnout, es el esquema explicativo que suele utilizarse al definirlo como “un estrés emocional crónico que se prolonga en el tiempo" (p. 85). Esto significa que la configuración del síndrome se explica a partir de un mecanismo adaptativo disfuncional (distrés) como reacción del organismo del individuo a las condiciones estresantes del entorno laboral. A todas luces, queda en evidencia un esquema discursivo-explicativo de afiliación funcionalista, en el que se transfiere una lógica explicativa propia del campo de la biología al campo de la psicología (peor aún, al campo de la sociología) y en el que podemos identificar el triple reduccionismo antes descripto: 
Anteriormente a la adopción del término burnout, la psicología contemporánea conceptualizó el estrés como algo que no es malo en sí mismo, sino una respuesta normal del organismo ante un estado de alerta, una tensión, un peligro. Es un mecanismo que permite que el organismo se adapte o reacomode frente a una cantidad de estímulos externos que le alteran el equilibrio habitual. Cuando el estímulo excede la capacidad de respuesta o hay una saturación de estímulos, el organismo no da abasto para procesarlos y el estrés deja de ser positivo. La persona estresada siente agotamiento y está más proclive a enfermarse. Las fuentes de estrés son siempre individuales y están condicionadas por los valores que el sujeto busca desarrollar en su trabajo. Por ello una fuente de estrés puede ser de poca importancia para algunos docentes mientras que para otros resulta ser motivo de conflicto. (p. 85)

Si bien es cierto que el esquema explicativo funcionalista sirve, no obstante, para comprender por qué se produce el agotamiento físico -y emocional-residual que conduce al desarrollo silencioso de enfermedades; no es tan útil para comprender por qué se producen los otros dos indicadores que constituyen la tríada sintomática tradicional del síndrome: la despersonalización y la sensación de bajo logro profesional ${ }^{5}$ (o el sentimiento de culpa como cuarto indicador agregado posteriormente). Tal vez este sea el motivo por el cual Maslach (citada en Cornejo Chávez y Quiñonez, 2009) ${ }^{6}$ prefiere definir el Síndrome de Burnout como un patrón psicológico de respuesta (una vivencia subjetiva) -como alternativa al esquema adaptacionista del estrés-, destacando los

\footnotetext{
${ }^{4}$ Las negrillas son propias del texto, las cursivas son nuestras.

${ }^{5}$ Cornejo Chavez y Quiñonez (2009) señalan que en las investigaciones sobre el estrés no se considera la despersonalización o distanciamiento emocional (cinismo) como una reacción asociada al mecanismo del estrés, por lo que sugieren que se trataría más bien de un mecanismo de defensa frente a la frustración laboral; mientras que respecto de la percepción devaluada del rendimiento laboral (realización personal) los autores señalan que parece relacionarse con la escasez de recursos para el desempeño laboral.

${ }^{6}$ Existe una discrepancia entre el texto de Devalle de Rendo y Vega (2006) y el de Cornejo Chávez y Quiñonez (2009) en relación a la definición que daría Maslach sobre el Síndrome de Burnout. En el primer texto se afirma y se cita a Maslach quien lo definiría como "estrés emocional crónico" (p. 85), mientras que en el segundo se afirma que sería la misma Maslach quien lo definiría como un "patrón de respuesta psicológico" (p. 75). Como en el primer texto la referencia a Maslach es de una publicación de 1982, mientras que en el segundo se citan publicaciones de 1996 y 2006; es muy posible que Maslach haya cambiado de perspectiva en el transcurso de esos años.
} 
factores del contexto social como sus determinantes causales e indicando que en sí mismo no constituye un trastorno psicopatológico.

Concebimos como patologización del Malestar Docente a la tendencia recurrente a definirlo por referencia al Síndrome de Burnout, amén de que no se lo considere a este último como un trastorno psicopatológico. Nos referimos más bien a la estrategia discursiva que tiende a rotular como "síndromes psicológicos" subjetivos o individuales a problemáticas complejas que merecen un análisis multidisciplinar y esquemas explicativos multicausales como de hecho lo amerita el fenómeno que englobamos bajo el término Malestar Docente.

\section{La Determinación Social del Malestar Docente.}

Lo que la delimitación del Síndrome de Burnout nos aporta a esta perspectiva de análisis más amplia, sobre todo en sus orígenes, es el hecho de que sus manifestaciones sintomáticas hayan sido observadas inicialmente en colectivos de profesionales dedicados a la atención de personas en situación de necesidad, sobre todo en el campo de la Salud y de la Educación (lo cual constituye un factor psicológico específico); posteriormente observadas también en otros campos laborales que no se encontraban definidas por ese rasgo indicado en las investigaciones pioneras (lo cual demuestra que no se lo puede reducir ni explicar a partir de factores subjetivos). Las investigaciones realizadas ulteriormente, teniendo en cuenta como factores causales del síndrome las condiciones laborales (edilicias, instrumentales, temporales, sociales, económicas, políticas, etc.) en que los trabajadores realizan su labor cotidiana, nos permiten delimitar y especificar los Determinantes Sociales de la Salud de los trabajadores en general y de los trabajadores de la educación en particular.

En relación a las condiciones laborales en que el colectivo docente realiza la tarea educativa podemos señalar aquellas que están relacionadas con un bajo presupuesto para solventar los recursos destinados a la educación: deficiencias edilicias (mantenimiento, saneamiento, instrumentos, ventilación, calefacción, etc.); aulas sobrepobladas (combinación de espacios reducidos o de aulas disponibles con un alto número de estudiantes por docentes); sueldos docentes precarizados (combinación entre salarios bajos y devaluación inflacionaria), horas de trabajo no remuneradas por no estar contempladas en el contrato laboral por designación de horas cátedra (combinación entre horas extraescolares y horas extraáulicas de dedicación institucional); e insumos de 
trabajo no contemplados en el poder adquisitivo de los docentes (más allá de todos los gastos relacionados con material didáctico hay que contemplar el alto costo de los insumos informáticos). Es necesario señalar que la escasez de recursos en el ámbito educativo, muchas veces es solventada por los aportes económicos de los mismos docentes o por recursos económicos generados por las mismas escuelas.

Respecto de las demandas laborales que configuran la relevancia social de la tarea docente, tenemos que señalar un progresivo incremento en las exigencias laborales a partir del desarrollo de políticas educativas desde una perspectiva de derechos: el desarrollo de una educación inclusiva genera un incremento de estudiantes que ingresan a las escuelas y una mayor heterogeneidad (diversidad) en las aulas; la permanente demanda de perfeccionamiento en nuevas tareas incrementa las horas destinadas al trabajo docente; la necesidad de atender problemáticas sociales que emergen en lo escolar (violencia familiar y de género, abuso sexual infantil, etc.) genera una extensión de las intervenciones de los docentes más allá de la labor pedagógica. Si relacionamos este aspecto con el anterior, podemos apreciar las contradicciones que se presentan entre los escasos recursos destinados a la educación y el incremento de las demandas sociales que desde la escuela se deben atender; además, podemos contraponer la desproporción entre la asignación del trabajo docente por cantidad de horas cátedra y la definición del rol laboral docente que excede el trabajo áulico.

Si tenemos en cuenta, finalmente, la valoración social de la docencia y de la educación nos encontramos con el desprestigio social de la educación y del colectivo docente: la permanente demanda social de que la educación debe cambiar porque es considerada como ineficiente; la realización de evaluaciones estandarizadas y descontextualizadas que arrojan resultados afines al prejuicio anterior; la permanente descalificación social y mediática del desempeño docente; el persistente conflicto salarial y la valoración negativa de la sindicalización docente; la desautorización institucional y familiar del estatus/rol docente como referente social frente a sus estudiantes; y la existencia de un imaginario social que simplifica la función docente a la transmisión de conocimientos, denegándole injerencia en el proceso formativo de sus estudiantes, muchas veces reservado como prerrogativa exclusiva de los padres. Si relacionamos este factor con los dos anteriores podemos apreciar una triple contradicción entre los siempre escasos recursos destinados a la educación, el incremento de las exigencias sociales del rol docente y la devaluación 
del estatus social de la docencia. Consideramos estos tres factores como los determinantes sociales que configuran lo que en este trabajo denominamos Malestar Social Docente.

\section{La Determinación Histórica del Malestar Docente.}

Hemos señalado la descalificación social de la educación y del colectivo docente como rasgo definitorio del Malestar Docente; y hemos indicado una contradicción ideológicodiscursiva entre las Políticas Educativas que plantean la educación desde una perspectiva de Derecho y la recurrente precarización de los recursos destinados a la Educación. Esta contradicción ideológica se vuelve palmaria -a nuestro juicio- cuando frente a los paros docentes se suele plantear un "supuesto" conflicto de derechos entre el derecho al paro docente y el derecho a la educación, fundado en una perversa ${ }^{7}$ apelación al "interés superior del niño". Se incurre en una contradicción porque en nombre del principio del "interés superior" se viola el principio de "integralidad”, ya que el Derecho a la Educación es "el derecho a enseñar y aprender" tal como es formulado tanto en nuestra Constitución Nacional (Art. 14) como en nuestra Constitución Provincial (Art. 11); y se viola el principio de "interdependencia" e "indivisibilidad"8 de los Derechos Humanos, ya que el derecho a aprender de los/as estudiantes no puede ser considerado de manera "indepentiente" y, en consecuencia, "disociado" del derecho a enseñar de los/as docentes. Desde una perspectiva hermenéutica integral, el Derecho a la Educación comprende tanto los derechos de los/as estudiantes como de los/as docentes y de la garantía de estos últimos dependen los primeros.

Aquí nos tenemos que hacer dos preguntas; la primera, ¿por qué se produce esta disociación en el derecho a la educación? y la segunda, ¿por qué se predica el desarrollo de una educación de calidad siendo los recursos destinados a la educación siempre

\footnotetext{
${ }^{7}$ La perversidad en juego en esta estrategia estriba en que de fondo se está utilizando la figura de niños, niñas y adolescentes como un "escudo gubernamental" para desarticular la lucha sindicalizada de los docentes, haciéndola pasar en su superficie como defensa del "interés superior del niño". Dicho de una manera más clara, el principio transversal de abogar por el "interés superior del niño" debería usarse como principio rector (un fin en sí mismo) en orden a resolver el conflicto y no como una estrategia política instalada procedimentalmente (como un medio) para ejercer violencia simbólica y psicológica contra el colectivo docente.

${ }^{8}$ Una perspectiva de defensa integral de los Derechos Humanos no solamente tiene en cuenta las normas "positivas" referidas a los derechos sino también los principios o normas "interpretativas" que dan coherencia al ordenamiento jurídico. Dentro de estos principios destacamos particularmente aquel que afirma que los Derechos Humanos son "indivisibles" e "interdependientes"; esto significa que "todos los derechos humanos, sean estos derechos civiles y políticos, económicos, sociales o culturales, son derechos dependientes entre sí y se encuentran relacionados. Debido a ello, la garantía de uno facilita la garantía de los demás y la privación de un derecho afecta negativamente los otros" (MJDH, 2013, p. 9).
} 
precarios? Para responder a la primera tenemos que decir que la defensa de los Derechos Humanos conlleva en sí misma y desde sus propios orígenes una ambigüedad ideológica:

La Declaración Universal de los Derechos Humanos en la posguerra (1949) se produjo en un mundo bipolar donde antagonizaban dos modelos de organización societal y se convirtió en uno de los recursos discursivos del bloque capitalista occidental en su accionar político y militar. De sus dos polos posibles - el uno con eje central en los derechos civiles y políticos individuales y el otro en los derechos colectivos y sociales- se sostuvo como discurso fundamental el primero. (Stolkiner y Ardila Gómez, 2013, p. 62)

Teniendo en cuenta este dato, podemos entender que la tendencia a interpretar los derechos como individuales, disociados de los derechos que le son correlativos, responde a la concepción liberal del Derecho; muy por el contrario, una perspectiva de defensa integral de los derechos se funda en una interpretación social de los Derechos Humanos, donde "su sujeto ya no es el individuo sino los colectivos humanos" (p. 63). La reducción que se produce al naturalizar que el Derecho a la Educación es el derecho a aprender y que este derecho puede colisionar con el derecho a enseñar, reproduce una concepción liberal del derecho cuyo rasgo más sobresaliente en este punto es la fragmentación del vínculo humano que constituye el fundamento antropológico de este derecho.

Kliksberg (2013) señala como una de las falacias instaladas en la opinión pública por la ideología neoliberal, la construcción de la idea del colectivo docente como un enemigo de la educación al demonizar la organización sindical y sus reclamos. Señala que es una estrategia utilizada para responsabilizar a los/as docentes de todos los problemas en educación e invisibilizar la presión y la injerencia de los organismos internacionales (Fondo Monetario Internacional y Banco Mundial) que presionan a los Estados a implementar políticas de ajuste inspiradas en recetas neoliberales. Carrizo (2012) señala más concretamente que este proceso de responsabilización del colectivo docente (que constituye la génesis histórica de su descalificación) se produjo en nuestro país durante el embate neoliberal producido en la década de los '90, el cual fue utilizado como pretexto para implementar una reforma educativa inspirada en esa misma ideología:

(...) De ser un agente de cambio en las escuelas en los '80, pasaría sin escalas a ser parte del problema de la educación. De allí en más el 
colectivo docente sería acusado de ser el principal responsable del deterioro de la educación, argumento que fue apropiado por ciertos sectores de la sociedad, sobre todo en los medios de comunicación. (p. 196)

Suárez (2003) analiza, más específicamente, los efectos que tuvo en términos escolares y pedagógicos la reforma educativa neoliberal argentina en los '90, señalando tres consecuencias: la dispersión curricular, la descalificación docente y la evaluación de la calidad educativa. La descalificación docente, en términos estrictamente pedagógicos, se dio a partir de una "impugnación de sus saberes y prácticas pedagógicas" (p. 45) por medio de una estrategia de capacitación masiva que consistió en transferir a los docentes un saber producido por especialistas - un saber ajeno a los contextos escolares- con la pretensión de cambiar las prácticas educativas:

El diseño de esas estrategias de capacitación se asentó entonces en el desconocimiento, la desconsideración o la descalificación de los saberes acuñados a través de la experiencia docente en las escuelas. De esta forma, se echó por tierra todo ese cúmulo de experiencias y saberes pedagógicos que los docentes aprenden y desarrollan prácticamente en las escuelas y las aulas. Saberes tácitos, silenciados o negados por la reforma que, más allá de sus bondades, actualización y pertinencia, se entroncan con la tradición pedagógica y la cultura escolares, es decir, con el conjunto de reglas básicas que gobiernan efectivamente la vida escolar y el aprendizaje de los alumnos, y sólo a partir del cual es posible vehiculizar algún cambio en los sistemas escolares y la enseñanza. (p. 48)

Lo que podemos observar a partir de estos datos es que la descalificación social e institucional del colectivo docente no constituye un hecho histórico aislado, sino que ha formado parte de una estrategia global de reforma educativa llevada a cabo por las políticas neoliberales de los '90. ${ }^{9}$ Esta reforma tenía como objetivo principal la reducción

\footnotetext{
${ }^{9}$ La avanzada neoliberal en Latinoamérica remonta sus orígenes a la crisis económica mundial de los años 70 -a raíz del agotamiento (dentro del Sistema Capitalista) del Estado de Bienestar keynesiano- en una disputa ideológica por el poder; que en el plano económico pone en entredicho la función de control del Estado respecto del funcionamiento del Mercado, reclamando para este último el derecho a una libertad cuasi absoluta; pero que en el plano de lo social, paradójicamente - o no-, predica un conservadurismo que atenta contra todas las libertades individuales, menos las económicas.
} 
presupuestaria de los gastos del Estado destinados a la Educación, lo que suponía también y necesariamente una reducción del salario docente, entre otros avasallamientos de los derechos laborales docentes. Este proceso de reforma educativa se pone en marcha con la Ley de Transferencia de Servicios Educativos ${ }^{10}$ en 1991 y con la Ley Federal de Educación en 1993; llegando a su fin -junto con su fracaso institucional y pedagógicocon la sanción de la Ley Nacional de Educación en el año 2006; proceso que a su vez debe comprenderse en el contexto de las consecuencias sociales producidas por las políticas neoliberales en nuestro país que desembocarían en la crisis económica del 2001. Ahora bien, esto no significa que el proceso de devaluación social del colectivo docente haya concluido en este período de la historia $y$, mucho menos, que se haya recuperado con las Políticas Educativas de los períodos siguientes, sino que más bien parece prolongarse de manera implícita bajo el modo de una inercia ideológica y como una sedimentación de sus efectos históricos remanentes en la educación. Esto significa que la descalificación institucional y social del colectivo docente seguirá más o menos en pie hasta nuestros días, aunque muchos otros aspectos de la educación hayan mejorado sustancialmente.

En este contexto de descalificación y devaluación de la educación y la docencia, quien de una manera irónica delta el desplazamiento de la figura del docente en el discurso pedagógico es Antelo (2012), cuyas palabras rescatamos de una entrevista televisiva:

Desde que hay educación hay voluntad de que las cosas cambien, es inexorable, no tiene retorno. Tal vez el cambio más interesante de los últimos años es el desplazamiento de la figura del docente en provecho de la figura de los niños, de los jóvenes; que eso trae consecuencias múltiples, básicamente la puesta en cuestión de la legitimidad del trabajo docente (...). [Los docentes] siguen siendo sospechados, en general todo el peso va a parar del lado del docente. Es

\footnotetext{
${ }^{10}$ La reforma se realizó bajo un "doble discurso" en relación a la descentralización; por un lado, toda una apología "democratizadora" de la "autonomía escolar" en pro de la "calidad" y la "eficiencia" educativas mientras que, por otro lado, se ejercía una transformación centralizada que pretendía modificar todo un sistema educativo a partir de una política de conocimientos "verticalista", "etnocéntrica" y "tecnocrática" (Suarez, 2010). Esta retórica distractora de la descentralización democrática, fue acompañada por el desfinanciamiento de la educación en las provincias, porque la verdadera intención de las leyes que la regulaban era la de constituirse en "el marco legal que legitimaba la reforma educativa de corte neoliberal que los organismos de crédito internacional imponían sin resistencia gubernamental y su pretensión de privatizar y mercantilizar la educación, desdibujando su tradicional carácter público y de derecho social" (Carrizo, 2012, p. 200).
} 
como escupir para arriba, si nosotros despreciamos a los docentes escupimos para arriba; la única alternativa que tenemos es trabajar con los docentes y no con los niños o con los jóvenes, como se dice. Si le queremos mejorar la vida a los niños o a los jóvenes, tenemos que trabajar con los docentes; con los adultos que de alguna manera transmiten la cultura, que hacen que vos y yo podamos conversar. Esta conversación se la debemos a algún adulto o a algún viejo, si no, no podríamos embocarle con el sujeto y el predicado. ${ }^{11}$

En términos de explicación causal, habíamos articulado anteriormente el desprestigio del trabajo docente como una consecuencia histórica de la influencia del discurso neoliberal en la Educación; ahora intentaremos defender la hipótesis de que ese discurso neoliberal se traduce en ciertas premisas del discurso pedagógico, que hemos denominado como complicidad ideológica del discurso pedagógico en el Malestar Docente. Entendemos por "complicidad ideológica" tanto la articulación discursiva de esas premisas y sus efectos de cuestionamiento sobre la legitimidad del trabajo docente, como así también sus consecuentes efectos en las prácticas pedagógicas. Para poder comprender la complementariedad entre ambas articulaciones causales podemos recurrir al concepto de "violencia simbólica" que Bourdieu (2005) describe como ese poder efectivo que garantiza en última instancia la dominación ideológica, cuando son las mismas víctimas quienes reproducen de forma invertida el mismo discurso que producen aquellos que tienen la pretensión de convertirlos en verdaderos aliados de sus propios intereses:

En un estado del campo en el que se ve el poder por todas partes, como en otros tiempos se rechazaba reconocerlo allí donde salta a los ojos, no es inútil recordar (...) que es necesario saber descubrirlo allí donde menos se ofrece a la vista, allí donde está más perfectamente desconocido, por tanto reconocido: el poder simbólico es, en efecto, ese poder invisible que no puede ejercerse sino con la complicidad de los que no quieren saber que lo sufren o incluso que lo ejercen. (p. 66)

Es en este anudamiento de complicidad ideológica, que se suele producir entre el victimario y la víctima -quedando este último entrampado sin saberlo o sin querer reconocerlo-, donde tendríamos que empezar a plantear las condiciones de posibilidad

\footnotetext{
${ }^{11}$ Las negrillas son nuestras.
} 
para un abordaje adecuado del Malestar Docente. Planteamos el término "abordaje" porque es el término apropiado para referirnos a la intervención de un malestar que hemos definido como social o colectivo. Desde aquellas otras perspectivas que interpretan el malestar reducido al Síndrome del Bournaut -ya sea que se lo entienda como estrés crónico o como perfil psicológico- y que lo consideran como un malestar individual, se suele hacer referencia a "estrategias de afrontamiento" que deberían usar los individuos para hacerse cargo de su propio padecimiento. Tales estrategias, suelen ser planteadas generalmente como la modificación de una mala gestión actitudinal frente al trabajo o como una amortiguación subjetiva de las condiciones laborales. Esta concepción individualista del malestar, también puede apreciarse en intervenciones surgidas del aplicacionismo de cierta vulgata psicoanalítica que, ante la incapacidad de "escuchar" el malestar vehiculizado por la "queja" docente y, al parecer, desconociendo el entrampamiento masoquista de la condición humana, cancela toda posibilidad de intervención social e institucional al usar el tan conocido clisé psicologista de "¿qué vas a hacer con esto?". El error en ciernes consiste en pretender abordar el malestar social docente con intervenciones que solo apuntan hacia los factores subjetivos, es decir, teniendo en cuenta solamente la determinación individual del malestar que, vale la pena decirlo, es la menos determinante de todas sus determinaciones.

\section{La Determinación Pedagógica del Malestar Docente.}

En esta dirección de abordar las condiciones de posibilidad de intervenciones que no queden estranguladas en planteos subjetivistas (o individualistas), pasemos a ubicar la génesis del desplazamiento de la figura del docente en el propio discurso pedagógico; esto equivale a decir, en el discurso ideológico que los propios docentes suelen reproducir sin saber que lo reproducen. Dicha génesis se produce en nuestro país en los inicios de la década de los '80 - al ritmo de la apertura democrática- a partir de la influencia del constructivismo psicogenético de Piaget, paradójicamente a contrapunto de la necesidad de superar un enfoque pedagógico tradicional, normalista, reproductivista y autoritario. La idea de un sujeto activo constructor de sus propios conocimientos y reconstructor de los contenidos curriculares, podríamos decir que fungió como algo más compatible con la concepción de un sujeto del aprendizaje acorde al calor democrático. En torno a este núcleo teórico se organizan otras ideas como la de formar sujetos autónomos intelectual 
y moralmente, capaces de desarrollar un pensamiento crítico y una actitud creativa en lugar de repetir sin evaluar primero lo que otros han dicho o hecho.

No podemos analizar aquí los errores propiamente epistemológicos de la teoría en sí y de todas sus implicancias en el campo educativo, simplemente vamos a destacar los efectos que produce en la relación pedagógica y en la experiencia educativa. Primero señalaremos que esta concepción del sujeto constructivista, individual y autónomo -que a nuestro criterio es particularmente afín a la ideología neoliberal- produce un reduccionismo epistemológico y un descentramiento del proceso educativo que comúnmente suele señalarse como la centralidad -o la importancia- de la relación del sujeto del aprendizaje con el objeto del conocimiento:

Una postura que coincide en esencia con estos argumentos es la que Coll y Martí (1990) han denominado planteamiento constructivista en sentido estricto. Según este planteamiento, se acepta que la actividad autoestructurante y constructiva del alumno tiene un lugar protagónico y central en las actividades ocurridas en el programa de clase; esas actividades de aprendizaje estarán principalmente determinadas por las operaciones y los mecanismos endógenos del alumno y, pedagógicamente, por sus actividades autoiniciadas (preferentemente en forma individual). (Hernández Rojas, p. 188) ${ }^{12}$

Este reduccionismo del aprendizaje al plano epistemológico produce, como segundo movimiento, un efecto necesario de disociación, corrimiento y desplazamiento tanto del acto de enseñar como del rol docente, respecto del aprendizaje y del rol del alumnado:

Si bien es propio del paradigma subrayar la actividad constructiva y la aplicación de los mecanismos estructurantes y estructuradores de los alumnos a los contenidos escolares, con posicionamientos como los anteriores se desplazaba claramente el problema de la enseñanza a la cuestión del aprendizaje; se asumían posturas en las que el docente pasaba a ocupar un lugar secundario, y se interpretaba la enseñanza como una actividad subordinada y secundaria a los procesos que rigen el desarrollo y el aprendizaje. (p. 188) $)^{13}$

\footnotetext{
${ }^{12}$ Las negrillas son nuestras.

${ }^{13}$ Las negrillas son nuestras.
} 
Dentro de la lógica de esta concepción psicológica y pedagógica -y como tercer movimiento-, el sentido fuerte del término "enseñanza" va a ser relativizado y reemplazado por la expresión "actividades del docente", dando lugar a un discurso que acentuará los aspectos puramente metodológicos de la enseñanza (didácticos); fundamentalmente centrados en las actividades, los intereses y la motivación de los/as estudiantes (por encima de lo curricular y de la intencionalidad educativa), rechazando y devaluando modalidades de enseñanza más verbales ${ }^{14}$ y expositivas:

En general, las propuestas sustentadas por el planteamiento constructivista surgidas hacia finales de los años setenta y durante la década posterior sostienen la necesidad de desarrollar un contexto didáctico que pueda ser estimulante y favorecedor para los alumnos. En este contexto, los alumnos tendrían la oportunidad de elegir y planear actividades que les parecieran interesantes y motivantes según su nivel cognitivo. La tarea docente estaría, hasta cierto punto, subordinada al diseño de ese contexto constituido por situaciones y experiencias relevantes para provocar el despliegue de actividades autoestructurantes. Esto, por supuesto, implicaría el trabajo de crear dichas actividades y experiencias con la intención de inducir indirectamente, y según las capacidades de los niños, el tratamiento de los contenidos curriculares (lo cual no es una tarea tan sencilla como parece). (p. 189) $)^{15}$

El auge del constructivismo psicogenético aplicado inicial y precozmente a la práctica pedagógica no tardó en mostrar el fracaso de sus promesas, fundamentalmente por el creciente descontento que produjo en las expectativas educativas de las familias al ver los pobres resultados educativos en sus hijos. No obstante, en lo sucesivo, las premisas

\footnotetext{
14 Esta destitución del carácter "simbólico" de la enseñanza -devaluado junto con lo que indiscriminadamente se califica como "enseñanza tradicional" - a favor de modalidades más "pragmáticas" del aprendizaje; no hacen otra cosa que anclar el desarrollo del pensamiento a las operaciones concretas (mediatizadas por las percepciones, las imágenes y las acciones), confiscando el desarrollo de las operaciones formales (mediatizadas por la palabra, los conceptos y la reflexión). Tal como lo advierte Sartori (1998): "Este es el proceso que se atrofia cuando el homo sapiens es suplantado por el homo videns. En este último, el lenguaje conceptual (abstracto) es sustituido por el lenguaje perceptivo (concreto) que es infinitamente más pobre: más pobre no sólo en cuanto a palabras (al número de palabras), sino sobre todo en cuanto a la riqueza de significado, es decir, de capacidad connotativa (p. 48).

${ }^{15}$ Las negrillas son nuestras.
} 
constructivistas serán reformuladas y revisadas en sus planteos teóricos y en sus proyecciones de aplicación al campo educativo. Por otra parte, tengamos en cuenta que estas premisas no van a llegar a desterrar por completo de las prácticas educativas las modalidades más tradicionales de la enseñanza. Sino que, más bien, se producirá cierta disociación entre los discursos y las prácticas pedagógicas; al mismo tiempo que una especie de amalgama entre prácticas expositivas y desarrollo actividades, bajo el modo de una modalidad mixta que va a configurar en la práctica esa ficción positivista que en la teoría va a ser denominada como "método de la enseñanza".

En la década de los '90, la reforma educativa utilizará como fundamento pedagógico de sus Políticas Educativas, ya no el constructivismo psicogenético (estructuralista) sino el constructivismo cognitivo (funcionalista). En este punto es necesario aclarar que lo que se conoce como constructivismo pedagógico, no constituye una unidad teórica homogénea, sino más bien una serie de principios pedagógicos que configuran una especie de discurso híbrido gestado a raíz de la hipótesis constructivista de Piaget, pero completado con la perspectiva sociocultural de Vigotsky a partir de las críticas al individualismo psicogenético; todo esto mediatizado por la Psicología Cognitiva norteamericana (Hernández, 1996). Esta última es la razón por la que se suele bautizar de “cognitiva” (también "constructivista") a la teoría de Vigotsky -toda una profanación epistemológica-, como estrategia ideológica que el cognitivismo americano ha utilizado para fagocitar la teoría bajo premisas individualistas, diluyéndole así sus fundamentos socialistas. Desde diferentes puntos de vista, la Psicología Cognitiva americana (recomposición de la crisis paradigmática conductista) es un híbrido epistemológico que lo que hace es incorporar la perspectiva cognitivista europea, pero rechazando su planteo estructuralista y reemplazándolo por el positivismo funcionalista de la metáfora computacional, como hipótesis o representación auxiliar de la mente. En síntesis, si el sujeto cognitivo postulado por el constructivismo europeo viene viciado desde sus orígenes con un planteo epistemológico individualista y endogenista, el cognitivismo americano lo completa con el enfoque pragmático, mecanicista, racionalista y positivista de su propia perspectiva ideológica, con una adulterada perspectiva social agregada como apéndice. Para poder posicionarnos frente al conglomerado de principios constructivistas, sin quedar entrampados en la homogénea ideología que le subyace, veamos la aclaración y la advertencia que al respecto realiza Hernández (1996): 
Que existan versiones del constructivismo no ha de ser un problema, pues ofrecen riqueza de puntos de vista; pero sí puede llegar a serlo que en la aplicación del constructivismo a la educación se presente a éste como teoría sustantiva de todo el proceso de escolarización y como referencia única para organizar la enseñanza. Sin embargo, no hay que perder de vista que el constructivismo (a pesar del tamiz social progresista derivado de la incorporación de la perspectiva vygotskiana) tiende a ofrecer una representación de la realidad, vigente hasta la modernidad, que separa mente y cuerpo, sujeto y objeto; se trata de una visión centrada en la racionalidad occidental, basada en la acumulación y clasificación de evidencias, fundada en la aplicación del método experimental como forma única y válida de conocimiento, favorecedora de un cierto individualismo cognitivo y competitivo y que presenta una sintonía con el modelo de gobierno y de economía neoliberal que se afianza en la actualidad en muchos países. (p. 54)

A fin de poder apreciar de una manera más concreta la contradicción y la disociación que se produce en la práctica educativa de los/as docentes al intentar aplicar los principios teóricos del constructivismo pedagógico, desde una perspectiva histórica de los efectos producidos por la implementación de políticas neoliberales; recurriremos a las conclusiones de una investigación realizada en nuestro país entre los años 2001 y 2005 con docentes de nivel primario y secundario:

$\mathrm{Al}$ entrevistar a estos docentes, referían intentar ubicarse en un modelo pedagógico constructivista. (...) Efectuamos numerosas entrevistas individuales y grupales, de carácter cualitativo; y una pauta recurrente era identificar en el discurso ideas "constructivistas": aprendizaje significativo, evaluación en proceso, trabajar con ideas previas, etc. Es así como, los docentes conocían las teorías -desde el punto de vista formal- ya que habían tomado cursos de capacitación diversos, incluso algunos continuaban su formación en licenciaturas y otros en posgrado, pero la decepción y frustración ante los resultados de la tarea era algo generalizado y persistente. En su discurso formal, los

\footnotetext{
${ }^{16}$ Las negrillas son nuestras.
} 
participantes, proclamaban adherir al constructivismo, pero en la práctica (que es donde se visualiza la "teoría en uso") estaban lejos de poder aplicar aquellos principios que se enunciaban. Efectivamente, las teorías en uso (implícitas), se estructuraban sobre una imagen de alumno "empobrecida" (con escasas posibilidades de logro, desmotivado para aprender, con problemas sociales y familiares, etc.)

\section{repercutiendo en la forma de pensar e implementar las propias} prácticas, aportando así al empobrecimiento de los resultados de la acción pedagógica (funcionando al modo de una profecía de autocumplimiento). (Butti, 2010, p. 6) ${ }^{17}$

Lo que aquí se pone de manifiesto es el desencuentro o la incongruencia entre la concepción teórica del sujeto del aprendizaje propuesto por las teorías constructivistas (sujeto universal, epistémico-cognitivo y abstracto) y la localización subjetiva de los sujetos concretos, determinados histórica y socialmente por sus condiciones reales de existencia. Lo que hemos decidido remarcar en la cita es el propio malestar que los docentes generan al producir una práctica educativa ineficiente, como consecuencia específica de esta determinación pedagógica del Malestar Docente; con la diferencia de que lo que allí se interpreta como "profecía auto-cumplida", nosotros preferiríamos conceptualizarlo como "violencia simbólica".

El callejón sin salida -y por ende, la contradicción teórica más palmaria, esquizofrénica y perversa- de las propuestas pedagógicas constructivistas es que embarcan a los/docentes en una apuesta educativa dirigida a un sujeto supuestamente activo, constructor, independiente y autónomo; pero a condición de que se ubiquen ellos mismos en el lugar de sujetos pasivos, reproductores, dependientes y heterónomos. ${ }^{18}$ Este

\footnotetext{
${ }^{17}$ Las negrillas son nuestras.

18 Esta interpretación debe contextualizarse con lo que Suárez (2003) señalaba respecto de que la capacitación masiva de los docentes, realizada durante la reforma, partía de la base de la descalificación del saber docente, con una lógica verticalista de "arriba hacia abajo" en la transmisión de un saber técnico especializado y con una propuesta de "autonomía" contradictoria: "a pesar de los «niveles de especificación curricular» y la «autonomía escolar», que prometían en sintonía con la retórica de la descentralización, los procesos de construcción curricular promovidos por la transformación curricular adoptaron una modalidad de implementación de tipo top-down. Como en casi todos los países en los que se implementó, este modelo de gestión de la reforma terminó restaurando el control centralizado de elementos estratégicos y definitorios del currículo, y cristalizando la pretensión de imponer verticalmente la mejora y el cambio a las escuelas y los docentes. De esta manera, la innovación de las instituciones escolares y la enseñanza supuso una direccionalidad que traccionó «de arriba hacia abajo» a los distintos actores del sistema escolar hacia nuevas posiciones, y que los interpeló de manera diferenciada de acuerdo con las
} 
desplazamiento de la figura del docente que al mismo tiempo desplaza la activa tarea de enseñar y de educar, es solidario con la desvalorización social del saber docente y con la descalificación social de la educación. Esta paradoja que se produce en el escenario pedagógico nos permite entender por qué, a pesar de todo, sobreviven modalidades tradicionales de la enseñanza, bajo una saludable resistencia ante semejante embate ideológico, no ya contra los/as docentes, sino contra el sentido de la educación misma.

En continuidad histórica con lo que Suarez (2003) indicaba en relación a la descalificación del saber docente como estrategia específica de la reforma neoliberal de los 90', tenemos que señalar que -durante los últimos veinte años- se ha producido en nuestro país una progresiva colonización del saber pedagógico por el discurso neurocientificista; expresiones tales como "el cerebro aprende", "neuroeducación" y "neurodidáctica", delatan la invasión discursiva de una interpretación biologicista de la enseñanza, del aprendizaje y de las dificultades en el aprendizaje. Las llamadas Neurociencias constituyen el fundamento de la Psicología Cognitiva norteamericana a partir de un núcleo epistemológico común: la concepción positivista del conocimiento, el esquema explicativo funcionalista del comportamiento y la comprensión mecanicista de lo humano. Como consecuencia de estas premisas en el ámbito educativo debemos señalar el avance de la patologización y la medicalización de niños/as y adolescentes, el incremento de profesionales especializados intervinientes en el escenario escolar y la captación de las infancias y las adolescencias por la industria farmacéutica. En nuestro medio es Zelmanovich (2018) quien plantea que la patologización y medicalización de los problemas escolares constituye una fuga de la función educativa; por otra parte, en diferentes investigaciones argentinas y de países vecinos (Inostroza, 2015; Maggi y Grillo, 2017; Barcia Fuentes, 2018; Chiavazza y Pintarelli, 2020) se evidencia una destitución del saber pedagógico por el saber médico en relación a las intervenciones educativas relativas a las dificultades en el aprendizaje, tal como específicamente lo señala Barcia Fuentes (2018):

En relación con la enseñanza formal, se posiciona el saber sobre las dificultades del aprendizaje fuera de las instituciones educativas, por lo que los equipos docentes quedan a la espera de los saberes médicos o

expectativas y roles prefigurados por el propio discurso de la reforma y de los especialistas curriculares." (p. 47) 
de otros especialistas para recibir orientaciones de cómo avanzar en el salón de clases. (p. 225)

En síntesis, si hacemos una apreciación global de este proceso de dominación ideológica reproducido en el discurso pedagógico, observamos una progresiva aniquilación del sentido de la Educación en su dimensión antropológica y en su función social, para instrumentalizarla en beneficio de los intereses mercantilistas afines a la ideología neoliberal. La idea central de que el sujeto del aprendizaje como individuo se relaciona autónomamente con los objetos del conocimiento a partir de su propia capacidad constructiva o de sus propios recursos cognitivos, es necesario cuestionarla; sobre todo, cuando se plantea que los sujetos que no disponen de esa capacidad y de esos recursos es porque se debe a un trastorno neurológico, a una predisposición genética, a un desequilibrio hormonal o, en última instancia, a un problema que el individuo tiene para adaptarse. A todas luces queda en evidencia el reduccionismo a lo biológico y el individualismo funcionalista como estrategia ideológica conservadora destinada a invisibilizar las determinaciones intersubjetivas, sociales e históricas de la Educación.

\section{La recomposición ideológica del sentido de la educación}

Lo más importante en la educación no puede ser la relación de los/os estudiantes con los objetos del conocimiento, como muchas veces se pregona; esta premisa constructivista/cognitivista reduce la educación y la enseñanza a un planteo meramente epistemológico y metodológico. Lo más importante en la educación es la relación pedagógica: ese vínculo asimétrico que se establece con la explícita intencionalidad de influir en la condición específicamente humana de la educabilidad; con la finalidad de producir una transformación en el ser del sujeto, que aunque libre de responder o no a semejante demanda, esta última se sostiene siempre bajo el sello irrenunciable de la insistencia y reconociendo la imposibilidad de medir sus resultados (Antelo, 2003).

Recuperar de este modo el fundamento antropológico (la dimensión humana) de la educación, nos permite darle un sentido que trasciende la dimensión puramente epistemológica y metodológica de la enseñanza (la transmisión de conocimientos). Desde esta perspectiva educar y enseñar no son asimilables, de modo tal que la experiencia de educar, todo lo que en ella se juega y todo lo que ella comprende, no podría reducirse nunca al acotado acto de enseñar. En este mismo sentido apunta la definición que ensaya Bleichmar (2010) al decir que la educación es la formación de sujetos éticos a partir de 
la transmisión de conocimientos; o la que podríamos recuperar de Antelo (2003) quien propone concebirla como la transformación del ser del sujeto a partir de la transmisión de conocimientos; $\mathrm{y}$, en esta misma línea, definir la enseñanza como la transformación de una manera de pensar, tal y como nos lo sugiere Bachelard (2000) al plantearnos esa apasionante manera de abordar los conocimientos previos -cuestionándolos-para hacer posible la transmisión del conocimiento científico.

Estamos proponiendo concebir la Educación desde una perspectiva más estructural a fin de poder superar la concepción funcionalista y mecanicista del constructivismo pedagógico que produce el desplazamiento de la figura del docente en el escenario pedagógico. De las teorías psicológicas del aprendizaje disponibles, la única compatible con este planteo -y la única que ha sido diseñada específicamente orientada a la educación- es la teoría socio-cultural de Vigotsky, que nos propone concebir al sujeto del aprendizaje como un ser concreto, definido por las condiciones reales de su existencia histórica, social y cultural. Ese estado real y concreto en el que el sujeto se encuentra, es el nivel de desarrollo natural y cultural que ha podido alcanzar por sí mismo y por su propio esfuerzo como individuo (Zona de Desarrollo Real). Lo que esta teoría nos propone es pensar la educación y la tarea pedagógica como una apuesta a futuro, imaginando la posibilidad de conducir a ese individuo a un nivel de desarrollo cultural mayor (Zona de Desarrollo Potencial), allí donde la diferencia se juega en la misma medida en que estemos dispuestos a complementar sus esfuerzos con nuestra propia ayuda como docentes y, eventualmente también, con la suma del esfuerzo y de la ayuda de sus propios pares (Zona de Desarrollo Próximo).

Semejante planteo solo es posible en una teoría que concibe al sujeto del aprendizaje como un sujeto social en un contexto de participación institucionalmente organizado; es decir, como un sujeto que aprende con otros, ayudando a otros y/o siendo ayudado por otros; pero donde los primeros "otros" que tienen que estar ahí para "construir" un andamiaje, que recubra temporalmente esa distancia trazada imaginariamente entre lo "real" y lo "potencial", son los/as docentes. Por eso, si analizamos esta teoría desde el punto de vista de la Ética -único criterio de demarcación válido en el campo de las ciencias sociales- nos encontramos con que fomenta la solidaridad en lugar del individualismo. Es en este punto donde la educación y la docencia nos revelan su naturaleza eminentemente política en el sentido en que lo plantea Freire (2006): 
No existe neutralidad en nada, no existe neutralidad en la ciencia, en la tecnología. Necesitamos estar advertidos sobre la naturaleza política de la educación (...). No puedo entender la educación fuera del problema del poder, que es político. Es necesario que los educadores estén advertidos de eso, porque en la medida en que el educador entiende que la educación es un acto político, él se descubre como un político. En verdad, el educador es un político, es un artista, él no sólo es un técnico que aprovecha las técnicas o que emplea la ciencia. Y por eso mismo él tiene que optar, y esa opción es política, no puramente pedagógica, porque no existe esa pedagogía pura. Entonces, en la medida en que el educador es un ser político, él tiene que tener una relativa claridad, por lo menos en relación con su opción política, lo que equivale a decir que él necesita preguntarse: a favor de quién trabajo yo en educación, a favor de qué, o en otras palabras, cuál es mi sueño como educador. Es como preguntar también contra qué estoy trabajando, porque yo conozco una cosa por su contrario de ésta; es necesario que yo sepa como educador con quién estoy. (pp. 42-43) ${ }^{19}$

Retomemos la reflexión sobre las condiciones de posibilidad respecto de un abordaje del Malestar Docente, pensándolas en relación a este particular condicionante en el que hemos centrado nuestro análisis. Repetidas veces hemos escuchado esas frase del sentido común referidas a la educación, cuyo rasgo más sobresaliente de su estructura gramatical es la disociación de dos cosas que deberían concebirse de manera integrada: "A la escuela se va a educar, no a hacer política", "La familia educa, la escuela enseña", entre otras que podríamos ir recogiendo si tenemos en cuenta como criterio de selección este particular modo de estructuración lingüística disociativa. Se trata de frases que repiten muchas personas, pero también se reproducen dentro del colectivo docente y la pregunta sería la siguiente: ¿qué tipo de conciencia tiene un/a docente de lo que está haciendo cuando reproduce este tipo de ideas?, ¿qué nivel de conocimiento se tiene respecto de las ideologías subyacentes a las que adhiere, más allá de dejarse seducir por la estética de su contenido más explícito? y ¿qué se sabe realmente respecto de las consecuencias pragmáticas que implica asumir esas ideologías como propias con tan irreflexiva

\footnotetext{
${ }^{19}$ Las negrillas son nuestras.
} 
certeza? Convengamos que de ninguna de ellas - ni de ninguna de todas las que puedan existir, así tan dispuestas a la repetición y a la reproducción-podría decirse que son el producto de ese tan mentado "pensamiento crítico" que supuestamente los/as docentes deberían generar en sus estudiantes. Lo mismo podríamos decir de ese otro tipo de constructos lingüísticos, ya no del sentido común, sino del "saber acumulado" (anquilosado) en las ciencias en general y en el discurso pedagógico en particular, que establecen principios explicativos y comprensivos de la realidad: "la adaptación del individuo al medio", "la importancia de la relación del sujeto del aprendizaje con los objetos del conocimiento", por solo referirnos a las que en todo nuestro análisis hemos decidido cuestionar fuertemente.

Apelamos aquí, como abordaje e intervención del Malestar Docente, a la propuesta freiriana del "proceso de concientización”, que no significa el simple acto psicológico de tomar conciencia, sino más bien la adquisición de una conciencia analítica y crítica que nos permita abandonar progresivamente el estado de alienación colectiva resultante del desconocimiento (falsa conciencia) de los verdaderos determinantes de nuestra propia opresión docente (valga realizar aquí el relevo del término hegemónico de "malestar"). Este trabajo progresivo de análisis y comprensión de las determinaciones históricas, sociales y pedagógicas que nos oprimen (conciencia de la opresión), nos permite decidir nuestro propio posicionamiento ideológico en el ejercicio de la docencia y apropiarnos de los medios adecuados para transformar colectivamente la realidad educativa en la que nos encontramos situados. Tal como lo expresa Freire (citado en Villalobos, 2000): "la concientización implica que, cuando el pueblo advierte que está siendo oprimido, también comprende que puede liberarse a sí mismo en la medida en que logre modificar la situación concreta en medio de la cual se percibe como oprimido" (p. 19). No se trata solamente de una concientización individual sino de reconocerse como parte de un proceso histórico colectivo y comprometerse con una actitud "utópica" que busque transformar la realidad de cara al futuro:

La concientización conlleva un doble requerimiento utópico: por un lado, denunciar la deshumanización, la opresión y la alienación; por otro, anunciar estructuras alternativas para la humanización y la liberación. El lenguaje de la protesta, la resistencia y la crítica va de la 
mano con el lenguaje de la posibilidad y la esperanza" (Villalobos, 2000, p. 19).

Desde esta perspectiva y volviendo sobre lo que hemos llamado la complicidad ideológica del discurso pedagógico, tenemos que advertir la relación que existe entre los usos del lenguaje, las ideologías políticas y el desarrollo del pensamiento. Es debido a esta relación que Freire sostiene que la concientización debe realizarse durante el proceso de alfabetización propio de la tarea educativa (Villalobos, 2000). Es a partir de la apropiación y dominio del lenguaje de nuestra cultura que nos hacemos partícipes, no solamente de un código lingüístico específico, sino también de una manera de percibir y comprender el mundo. Vamos a dejar de lado todo lo que podríamos decir respecto de los usos del lenguaje y de los discursos por fuera de los ámbitos académicos, ya que lo que aquí nos interesa es enfocarnos en el discurso pedagógico, el discurso que nosotros utilizamos para diseñar nuestras prácticas pedagógicas. Las palabras que utilizamos, los discursos que asumimos en los usos de nuestro propio lenguaje (sea oral o escrito), las teorías y los esquemas explicativos a los que adherimos; no son herramientas objetivas que utilizamos solamente para nombrar la realidad de alguna manera, ni mucho menos modos alternativos de referirnos a ella. Son, en realidad, aparatos ideológicos que, a medida que los vamos incorporando por medio de nuestros propios procesos de aprendizaje, lo primero que hacen es configurar nuestra manera de pensar y de concebir la educación (en términos de Vigotsky, son herramientas internamente orientadas) y, secundariamente, tienen el efecto de orientarnos en nuestras prácticas educativas (herramientas externamente orientadas). Esta es la razón última por la que hemos decidido enfocar nuestro análisis en los aspectos ideológicos del discurso pedagógico que colaboran (en complicidad ideológica) con el Malestar Docente y consideramos que es en esta dimensión donde deberían enfocarse las intervenciones destinadas al abordaje más inmediato del mismo, por parte del colectivo docente. Si es el mismo colectivo docente el que reproduce los discursos de la dominación, entonces es el mismo colectivo docente el que garantiza que la dominación, no solo se produzca, sino que también se reproduzca.

\section{CONCLUSIONES}

El cuestionamiento inicial de la asimilación del Malestar Docente al Síndrome de Bournaut como patologización del malestar, no ha tenido otro sentido que el de visibilizar las condiciones históricas y sociales que lo definen como un problema comunitario en 
lugar de reducirlo a un problema individual. Habíamos definido tres factores como los determinantes sociales que configuran el Malestar Social Docente: los recursos económicos insuficientes destinados a la Educación, el incremento de exigencias laborales docentes en el desarrollo de políticas educativas inclusivas y el desprestigio social de la educación y del colectivo docente. La contradicción que inmediatamente se pone en juego al confrontar entre sí a estos factores es el sinsentido que se produce al pretender lograr una educación de calidad mezquinando recursos materiales y a partir de la devaluación de los agentes sociales que tendrían que llevarla a cabo. Como hemos visto al analizar los determinantes históricos del Malestar Docente, esta paradoja programática responde a los mandatos neoliberales, donde el discurso de la "calidad" es simplemente una estrategia encubridora.

La introducción de un determinante pedagógico del Malestar Docente, nos permitió poner en evidencia la reproducción discursiva que, bajo el modo de una violencia simbólica, constituye la complicidad de las teorías pedagógicas con la ideología neoliberal. En términos generales nos hemos referido a la concepción positivista del conocimiento, a la explicación funcionalista del comportamiento y a la comprensión mecanicista de lo humano; en términos más específicos, señalamos la reducción de la educación a su dimensión epistemológica y metodológica (la importancia de la relación del sujeto del aprendizaje con los objetos de conocimiento), el desmantelamiento de la dimensión antropológica (lazo social o vínculos pedagógicos), el emplazamiento del sujeto individualista y meritocrático en el centro de la escena pedagógica (constructor de sus propios conocimientos a partir de sus propios recursos cognitivos), el desplazamiento de la figura del docente a una función meramente instrumental (un guía, un acompañante, un técnico de la didáctica) y el relevo del saber docente por el saber neurocientificista en la comprensión de los proceso de enseñanza-aprendizaje y sus dificultades (el cerebro aprende, neuroeducación, neurodidáctica, patologización y medicalización). Es a partir de este determinante que podemos comprender el efecto de despersonalización que se encuentra en la tríada sintomática del Síndrome de Bournaut, producto del desmantelamiento subjetivo (desubjetivación) de la dimensión antropológica de la Educación.

En orden a perfilar un abordaje del Malestar Docente hemos planteado una recomposición del sentido social de la educación. En términos generales, la ingeniería discursiva de 
fragmentación que hemos analizado produce una descomposición del sentido social y político de la Educación y, en particular, el proceso histórico de desplazamiento de la figura del docente culmina en un proceso de desubjetivación de las infancias y adolescencias afín a intereses mercantilistas e incompatible con la perspectiva de protección integral de sus derechos. El proceso de concientización de Freire plantea las condiciones de posibilidad para que el colectivo docente pueda asumir una actitud crítica, analítica y política ante este proceso de colonización y dominación ideológica presente en el discurso pedagógico. La teoría sociocultural de Vigotsky, por su parte, brinda las coordenadas necesarias para recomponer el sentido social de la educación. Esta teoría plantea un sujeto del aprendizaje social e históricamente situado, una comprensión de la educación como desarrollo social comunitario y una recomposición de la figura del docente como agente social de mediación cultural. Es en esta apuesta de abordaje del Malestar Docente que proponemos la comprensión del sentimiento de bajo rendimiento profesional, constitutivo de la tríada sintomática del Síndrome de Bournaut, como expresión de la ineficacia de las intervenciones docentes determinadas por concepciones individualistas y reduccionistas. La potencialidad heurística del concepto de Zona de desarrollo Próximo, permite superar la visión individualista y el reduccionismo neurocientificista del sujeto del aprendizaje, al ubicarlo en una zona potencial que lo promueve más allá de sus propias posibilidades y dificultades, en esa diferencia solidaria que se establece entre la promoción del esfuerzo individual y la colaboración comunitaria.-

\section{REFERENCIAS BIBLIOGRAFICAS}

Antelo, E. (2005) Notas sobre la (incalculable) experiencia de educar. En G. Frigerio y G. Diker (Comps.) Educar: ese acto político. Buenos Aires: Del Estante Editorial.

Antelo, E. (2012) Estanislao Antelo - AP 99 [Video]. Agenda Pública [agendapublicaunr]. Youtube. https://www.youtube.com/watch?v=qE0Xifb8rSk

Bachelard, G. (2000) La formación del espíritu científico. Contribución a un psicoanálisis del conocimiento objetivo. Buenos Aires: Siglo XXI.

Barcia Fuentes, A. (2018) ¿Cómo actúan los maestros ante las dificultades de aprendizaje? En A. M. Fernández Carballo y J. Corbellini Venturini. (Dir.) Dificultades ante el aprendizaje: un abordaje multidiciplinario. Uruguay: FHCE. https://www.academia.edu/37629092/Dificultades_ante_el_aprendizaje_Un_abo 
$\underline{\text { rdaje_multidisciplinario_Fern\%C3\%A1ndez_Caraballo_y_Venturini_Corbellini }}$ Direcci\%C3\%B3n_pdf

Bleichmar, S. (2010). Violencia social, violencia escolar: De la puesta de límites a la construcción de legalidades. Buenos Aires: Noveduc.

Bourdieu, P. (2000) La dominación masculina. Barcelona: Anagrama.

Chiavazza, A. A. y Pintarelli, A. (2020) Incidencia de la patologización y medicalización en saberes, actitudes y estrategias docentes frente a infancias. Ciencia y Profesión. Anuario de la Facultad de Psicología de la Universidad Nacional de Córdoba, 5(8), pp. 52-76.

https://revistas.unc.edu.ar/index.php/aifp/article/view/33323/33748

Cornejo Chávez, R. y Quiñónez, M. (2007) Factores asociados al malestar/bienestar docente. Una investigación actual. REICE. Revista Electrónica Iberoamericana sobre Calidad, Eficacia y Cambio en Educación, 5(5), pp. 75-80. https://www.redalyc.org/pdf/551/55121025011.pdf

Devalle de Rendo, A. y Vega, V. (2004) La diversidad en la docencia: El modelo de rizoma. Buenos Aires: Troquel S. A.

Freire, P. (2006) Pedagogía de la tolerancia. Buenos Aires: Fondo de Cultura Económica.

Hernández, F. (1996): Psicología y educación. Cuadernos de Pedagogía, 253(¿), pp. 5056. https://docer.com.ar/doc/sxnn1es

Hernández Rojas, G. (2004) Paradigmas en psicología de la educación. Buenos Aires: Paidós.

Inostroza, F. A. (2015) Análisis crítico del discurso sobre la noción de estudiante con dificultades en el aprendizaje en el marco de un proyecto de integración escolar en una escuela municipal de Chile. Revista Mexicana de Investigación Educativa, 20(66), pp. 941-958.

http://www.scielo.org.mx/scielo.php?script=sci_arttext\&pid=S140566662015000300011\&lng=es\&nrm=iso\&tlng=es

Kliskberg, B. (2013) Seis falacias sobre educación. El Informe Kliskberg [Video]. [Gustavo Vega]. Youtube. https://www.youtube.com/watch?v=3e79Xx2n29Y

Maggi, L. y Grillo, J. J. (2017) Fracaso escolar y patologización de la infancia. Repositorio Institucional de la Universidad de La Plata. 
http://sedici.unlp.edu.ar/handle/10915/69638

Mejía, L. M. (2013) Los Determinantes Sociales de la Salud: base teórica de la salud pública. Revista de la Facultad Nacional de Salud Pública de la Universidad de Antioquía, 31(1), pp. 28-36.

http://www.scielo.org.co/pdf/rfnsp/v31s1/v31s1a03.pdf

Ministerio de Justicia y Derechos Humanos (MJDH) (2013) Políticas públicas en salud mental: de un paradigma tutelar a uno de derechos humanos. Buenos Aires: Secretaría de Derechos Humanos.

http://www.jus.gob.ar/media/1199853/pol_ticas_p_blicas_en_salud_mental.pdf

Sartori, G. (1998) Homo Videns: La sociedad teledirigida. Buenos Aires: Taurus.

Stolkiner, A. y Ardila Gómez, S. (2012) Conceptualizando la Salud Mental en las prácticas. VERTEX. Revista Argentina de Psiquiatría, 23(?), pp. 57-67. http://www.psi.uba.ar/academica/carrerasdegrado/psicologia/sitios_catedras/obli gatorias/066_salud2/material/unidad1/subunidad_1_1/stolkiner_ardila_conceptu alizando_la_salud_mental.pdf

Suárez, D. (2003) Dispersión curricular, descalificación docente y medición de lo obvio. Revista Novedades Educativas, 115(?), pp. 44-49.

https://es.scribd.com/document/485995618/Suarez-Daniel-H-Dispersion-CurricularDEscalificacion-Docente-y-Medicion-de-lo-Obvio-Noveduc-N\%C2\%BA-155

Villalobos, J. (2000) Educación y concientización: legados del pensamiento y acción de Paulo Freire. Educere, 4(10), pp. 17-24.

https://www.redalyc.org/pdf/356/35641003.pdf

Zelmanovich, P. (2018) "La patologización de los problemas es una fuga de la función de la escuela." La Capital [Online 10-11-18].

https://www.lacapital.com.ar/educacion/la-patologizacion-los-problemas-es-una-fugala-funcion-la-escuela-n1700307.html 